\title{
SALT CONTAMINATION OF WOODEN MATERIALS: THE CASE OF TRONDHEIM (NORWAY) WAREHOUSES
}

\section{CHIARA BERTOLIN ${ }^{1 *}$, MARCIN STROJECKI ${ }^{2}$, LAVINIA DE FERRI ${ }^{1}$, GIULIA GROTTESI $^{3}$ AND ANNA MARIA SIANI ${ }^{3}$}

\author{
Department of Mechanical and Industrial Engineering, Norwegian University of Science and \\ Technology, Trondheim, Norway. \\ e-mail: chiara.bertolin@ntnu.no, https://www.ntnu.edu/employees/chiara.bertolin (*corresponding \\ author); lavinia.de.ferri@ntnu.no \\ ${ }^{2}$ Jerzy Haber Institute of Catalysis and Surface Chemistry, Polish Academy of Sciences, Krakow, \\ Poland \\ ncstroje@cyf-kr.edu.pl, http://www.ik-pan.krakow.pl/Szczegoly-profilu.293+M5f6db5c33ab.0.html \\ ${ }^{3}$ Physics Department, La Sapienza University, Rome \\ 1655269@studenti.uniroma1.it \\ annamaria.siani@uniroma1.it.
}

Keywords: wood, acoustic emission, vacuum microbalance, salts; moisture meters.

\begin{abstract}
Warehouses are big architectonical structures mostly made of spruce wood and utilized as storage buildings principally by food traders in Northern Countries. Trondheim's warehouses currently observable along the river Nidelva, date back between the $17^{\text {th }}$ and half of the $19^{\text {th }}$ century were mostly used to stock and process fish. Therefore, where the food goods were stored, residuals are expected to be still present and/or to be responsible for the formation of alteration products on the wooden surfaces as well as inside the wooden structure.

Here we propose a characterization of residual and neo-formed compounds inside and on the surface of wooden logs by means of vacuum microbalance that allowed both to individuate the type of salts, as well as, to estimate the maximum water film thickness adsorbed on the wooden samples at 93\% of $R H$. These data have been related to variations in the acoustic emission (AE) intensity detected at the log surface and to the wood moisture content measured with capacitive and resistance operating moisture meters. The application of three independent techniques have allowed obtaining interestingly information indicating their potentiality as decay assessment techniques in the field of historical materials and specifically in the study of salts weathering on wood. The methodology allowed identifying a clear relationship between the amount of water in logs as a function of their distance from the ground and variations in the amplitude of the acoustic emission signals.
\end{abstract}

\section{INTRODUCTION}

Wood based warehouses represent unique historical coastal buildings with peculiar construction features ascribable to the Norwegian construction tradition [1]. The main problem for these buildings were both to resist local weather conditions (strong winds, rain, high humidity, low temperature) and being functional for the specific needs of fishing/trading societies. Nowadays these structures are still present in cities developed starting from the Middle Age on the coasts and whose economy was based on the export of stockfish (dried cod) [2]. Trondheim has always been one of the most important Norwegian ports even if warehouses 
were constantly destroyed by fires and re-built always on the same sites and following the same construction rules established in the 12th century [2]. The quite big structures along the river (Nidelva), mostly made of spruce wood, date back to between the 17 th and $\sim 1950$ and were generally created as a combination of wood frames and log structures permitting the formation of many different space distributions. They were used as storage buildings mainly by food traders and merchants trading in other goods such as lumber, copper (from the Røros mines), flour, grain, sugar and precious textiles [2].

Food storage is supposed to leave residuals, that could also be responsible for the neoformed products (salts) on the wooden surfaces as well as inside the wooden structure. Wood alteration phenomena driven by salts have almost never been studied in the field of cultural heritage, basically because wood was usually employed for mobile artworks and only in few specific geographical regions such as Norway it was used as building material. Additionally, very few areas with historical wooden buildings are in a marine environment and this is the case of Scandinavia or other Antarctica regions. Consequently, the few studies regarding wood salt degradation of heritage buildings have been dealt with phenomena strictly associated with these peculiar environmental conditions [3-7]. Salts efflorescence and sub-efflorescence on wood were only rarely studied $[3-6,7,8-10]$ and in many cases researches are related to the influence of chemicals used for preservations purposes (pesticides, flame retardants, consolidants, etc.) As reported [7], such phenomena could be related to chemicals solubility by free water leakage and to the following crystallization into the porous microstructure of wood and on the surface in form of salts.

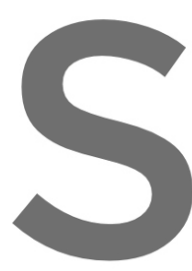

The final step in the fuzzy wood, that manif induced and intensified structures of wood. Suc growing of salt crystals
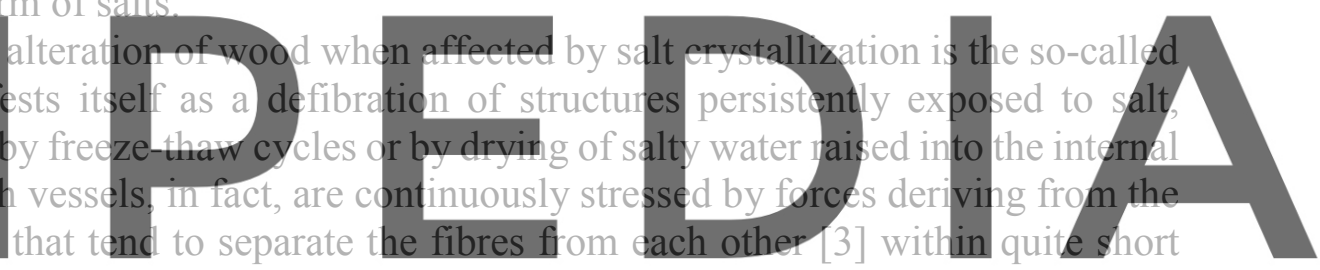

periods of time (up to 5 years). Furthermore, when water evaporates salts concentrate leading

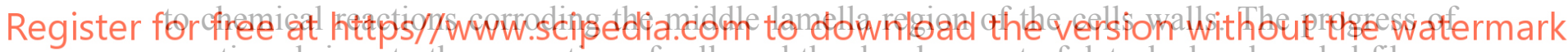
reactions brings to the separation of cells and the development of detached and eroded fibres, strongly affecting the stability of structures in ca. 30 years $[3,5]$.

At the opposite, the detrimental effects of salts on stone-based structures have been widely investigated, also by means of Acoustic Emission (AE) [e.g. 11], a technique widely exploited in many fields but still representing a quite innovative diagnostic tool in the field of cultural heritage. Only few studies, in fact, are currently available on this topic when compared with the total amount of publications related to the use of other diagnostic tools in artworks, and they are mostly related to wooden based artworks [11-15] or to architectural heritage sites [16-18]. Being a non-destructive technique (NDT), AE has been mostly utilized during monitoring campaigns in order to obtain a fast detection of newly formed cracks or older crack propagation within the frame of preventive conservation projects, structural health monitoring of restored elements [19], evaluation of seismic risks [20,21], and detection of infestation of xylophagous insects [13]. This is because dimensional changes of wooden objects are related with changes in temperature and relative humidity, and with seismic or biological activities. AE lets the very fast recognition of these events even when occurring at a very low intensity level (e.g. due to microcracks appearance) 
Here, acoustic emission, sorption isotherm and three different moisture content measurements (i.e. 2 capacitive and 1 resistance operating) techniques are proposed to investigate the state of one of the last almost original and never studied warehouses of Trondheim (Norway). The proposed research reports about residual and neo-formed salts, whose chemistry and concentration in four different structural elements or logs has been related to differences registered in terms of acoustic emission amplitude and moisture content in order to obtain information about their state of conservation.

\section{MATERIALS AND METHODS}

Three logs (Norwegian spruce - Picea abies) at different heights (Figure 1a) of the internal wall indicated in Figure 1b (ground floor) were tested, as well as a spruce trunk in the warehouse (Figure 1c) basement.
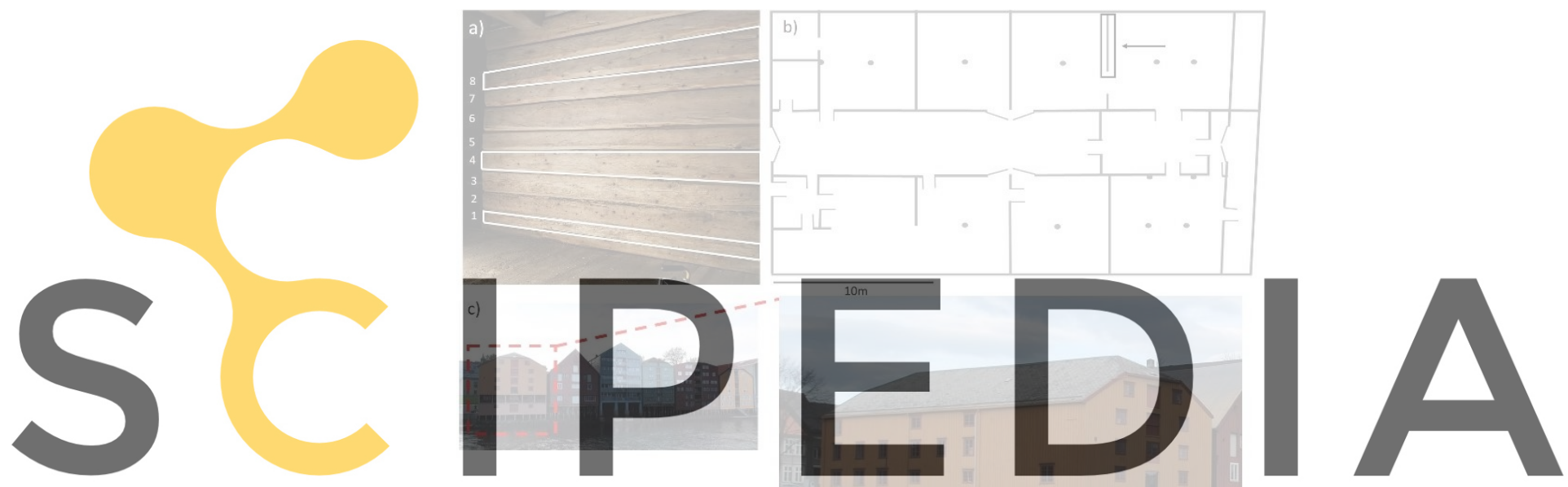

Register for free at https//www.scipedia.com to

to download the version without the watermark

Figure1: a) Selected logs; b) Plan of the ground floor. The studied wall is circled, and the arrow indicates the tested side; c) The warehouse studied in Trondheim.

Samples to perform the water vapor sorption experiments were collected from every log and from the trunk using a drill bit $(\varnothing=2 \mathrm{~cm})$. Measurements were taken gravimetrically by means of a vacuum microbalance from CI Electronics Ltd, following the methodology described in Bratasz et al. 2012. Adsorption branches of the water vapor isotherms were determined later in the laboratory at room conditions $\left(\mathrm{T}=24^{\circ} \mathrm{C}\right)$ and for a full range of water vapor relative pressures. Typically, a $0.1 \mathrm{~g}$ wood fragment was weighted and outgassed prior to the measurement under a vacuum of a residual pressure of less than $0.1 \mathrm{~Pa}$ in order to move the air out of the wood and to eliminate most of the species physisorpted during the storage of the sample, especially adsorbed water. The process was fully automated and measuring of 10 adsorption points took on average several hours. 
Acoustic emission measurements were carried out by means of an AMSY-6 AE system (Vallen System GmbH, Icking, Germany). Each AE channel was equipped with a VS900-M sensor (frequency operating range $=100-900 \mathrm{kHz}$ ) in line with an AEP5 signal preamplifier ( $2.5 \mathrm{kHz}$ to $2.4 \mathrm{MHz}$ ). Each channel, sensor and preamplifier combination was kept fixed during the monitoring of the logs. The rearm time and duration discrimination time were set to 3.2 and $1.6 \mathrm{~ms}$, respectively, while pre- and post-trigger times were maintained equal to 0.2 and $0.4 \mathrm{~ms}$, respectively. The signal sampling rate used to calculate the primary AE parameters was 10 $\mathrm{MHz}$, whereas a value of $1 \mathrm{MHz}$ was used to record the transient signal. Signals were acquired after applying a low-pass filter of $500 \mathrm{kHz}$, then the first peak amplitudes (i.e. maximum value of the first amplitude peak) were integrated to obtain the amplitude values to be verified in the attenuation models presented here. The disturbance caused by environmental noise was filtered using the system-predetermined threshold level set to $40 \mathrm{~dB}$. All the monitoring campaign was conducted under environmental condition: relative humidity $(\mathrm{RH})=75 \%$, and temperature $(\mathrm{T})$ $=6-10^{\circ} \mathrm{C}$

During the monitoring, at the surface of each selected logs, an acoustic emission events was simulated using the pencil lead break (PLB) method, first proposed by Nelson N. Hsu [22]. Each PLB was performed following the requirements given by the standards $(\varnothing=0.3 \mathrm{~mm}$ and 2H lead) ASTM E2374-16 2016 and ASTM E976-15 2015 [23,24]and executed five times to

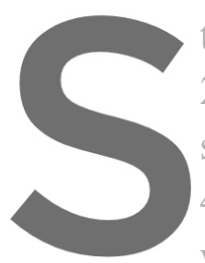
test the homogen eous sensors response. Qn ev
$25 \mathrm{~cm}$ from each other, was created to locate the
sensor was fixed to the wood surface by means
$4 \mathrm{~cm}$ above every sensor location. The san
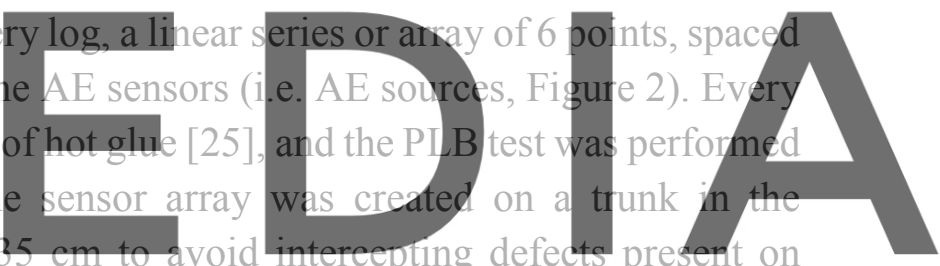

wood. During the data analysis, collected data have been filtered following the constrains

Register fopfree at hattes/dwww scjpedia com to downlead the vełsian without the watermark

fitting of the amplitude attenuation curve was used to obtain comparable distance values [25].

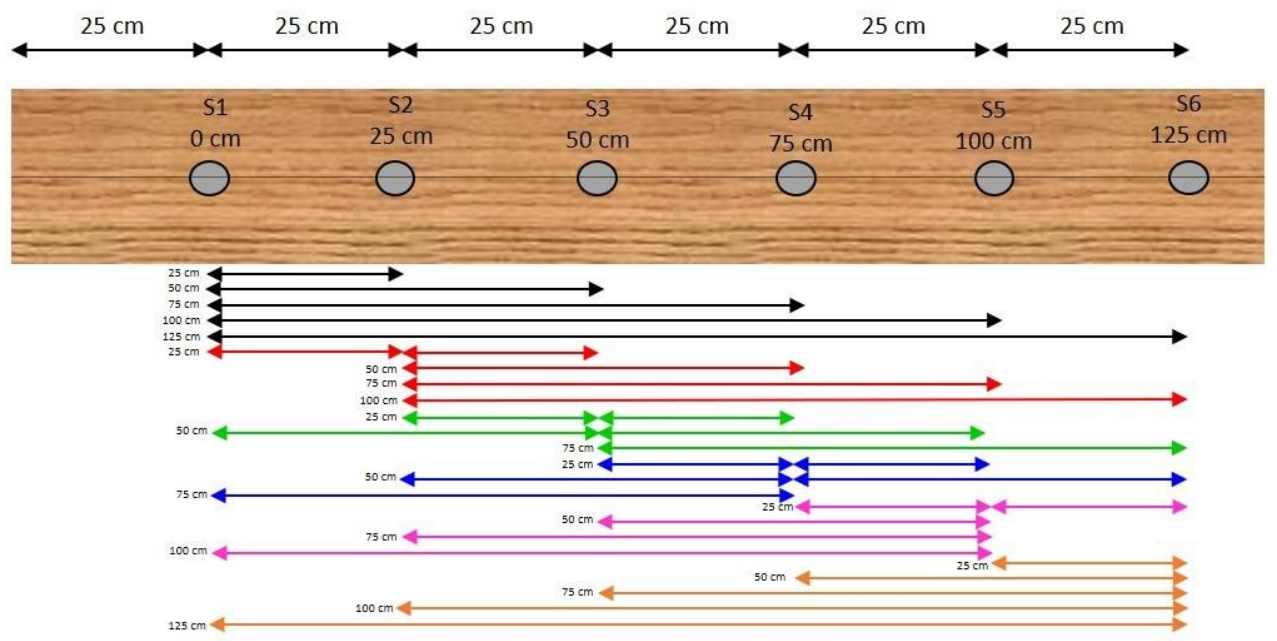

Figure 2: Scheme of sensors array and of distances between AE source (PLB) and sensors. 
Table 1: Required level of accuracy during an AE event obtained by the PLB test procedure

\begin{tabular}{cc}
\hline Parameter & Required level of accuracy \\
\hline Amplitude & $40<\mathrm{dB}<95$ \\
COUNTS & $>3$ \\
Rise Time & $>3 \mu \mathrm{s}$ \\
Duration & $>3 \mu \mathrm{s}$ \\
Root Mean Square & $\leq 10 \mu \mathrm{V}$ \\
\hline
\end{tabular}

Moisture content (MC) measurements on logs and trunk were taken by means of a Trotec T660 capacitive moisture meter (Trotec, Wels, Austria). The capacitive measurement method is non-destructive since the dielectric constant $\varepsilon$ of the wood is determined via the highfrequency field of the capacitor. When wood is altered by moisture content, $\varepsilon$ increases. In the T660 the generated electric field by the sensor (i.e. the measurement field) forms between the active spherical head and the substrate that is to be assessed up to a depth of about $0.5-4.0 \mathrm{~cm}$ (see Figure 3, left), keeping the probe sphere $(\varnothing=1.2 \mathrm{~cm})$ perpendicular to the structure surfaces. Being the radius of a Log of about $15 \mathrm{~cm}$, this means the measurement field is representative of the MC within ca 13\% depth of the whole Log. With the T660, three measurements were taken in the same points where the PLB tests were performed on every investigated structural element.(three Logs and the Trunk). The second utilized moisture meter i.e. Trotec T610 microw method too. Being water electromagnetic field it values, which increase of more than one order
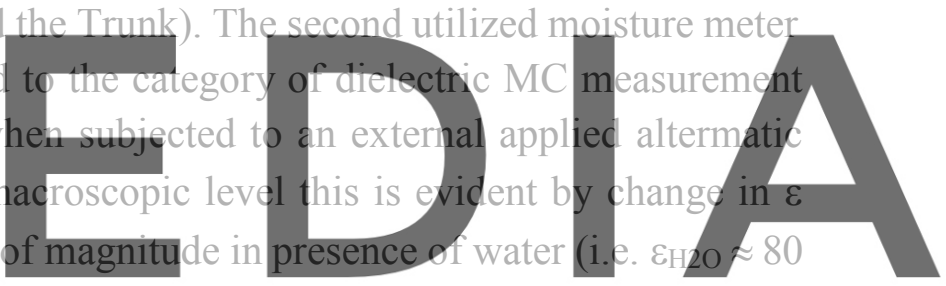

while $\varepsilon_{\text {Dry spruce }} \approx 1-3$ ). In the microwave range, beside the high dielectric constant of water (i.e.

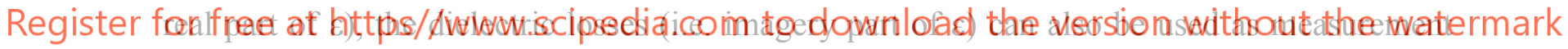

parameter. An advantage of this second NDT is, in fact, that the influence on the resistive losses caused by ionic conductivities due to the salts presence/weathering is reduced within the operating frequency of the instrument i.e. $2.43 \mathrm{GHz}$. At such frequency these losses are virtually negligible compared with dielectric ones, indicating that the microwave method is theoretically independent by the presence of salts. In reality, as reported by experimental tests conducted by Camuffo and Bertolin in 2012 [26], the efflorescence is almost not noticeable when RH is below the salt deliquescence level very because the water layer adsorbed in the superficial salt efflorescence is a very small fraction of the whole MC into the bulk material. However, when $\mathrm{RH}$ exceeds the deliquescence level, the thin aqueous film that forms on the surface reflects the signal giving the appearance of a damp material (e.g. approaching the Fiber Saturation Point (FSP) conditions). T610 microwave sensor contains an antennae assembly that enable a measurement field up to a penetration depth of ca. $30 \mathrm{~cm}$ i.e. the whole dimensions of the monitored Logs (see Figure 3, right). Finally, the third and last moisture meter used was the Trotec T3000 which uses the resistance or conductivity measurement principle i.e. an electrical 
current generated in the device and conducted in the wood thanks to the insertion of 2 electrodes or pins (length $=2,0 \mathrm{~cm}$, see Figure 3, central). With higher water content in wood the conductivity increases and the resistance reduces (i.e. water is inversely proportional to measured resistance). The resistance curve was corrected for the tested wooden material i.e. spruce and automatically adjusted as a function of the surface wood temperature that was in equilibrium with the air T. Surface and air T were detected using a thermistor NTC sensor.
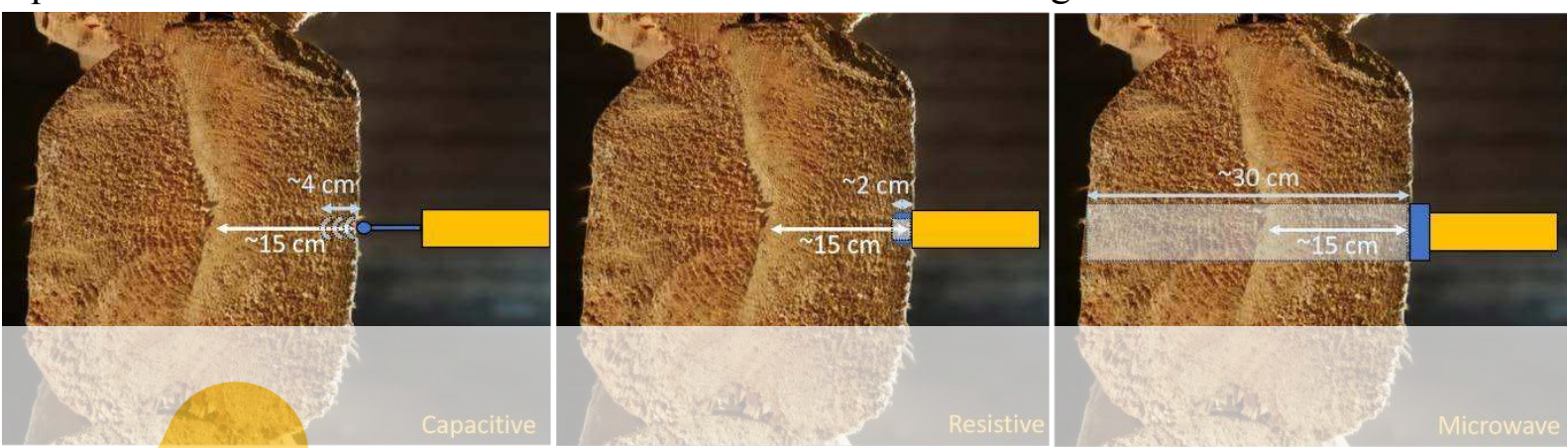

Figure 3: Scheme of the penetration depth of the three moisture meters into the wooden Log.

\section{DISCUSSION OF THE RESULTS}

Two alteration forms have been observed on the investigated wooden elements: salts efflorescence and what was interpreted as starting of fuzz by a quite soft and easil

The adsorption isothe crystallized inside the structur Ammonium Nitrate $\left(\mathrm{NH}_{4} \mathrm{NO}_{3}\right)$

Table 2 resumes trends for the 4 analyzed samples reporting the statistical thickness of the water

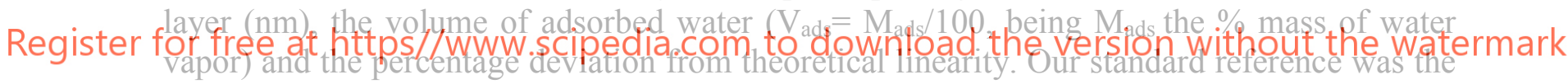
trunk element as it was a clear wood sample with no salts presence.

Table 2: Statistical thickness of the water layer (nm), volume of adsorbed water (\%) and percentage deviation from theoretical linearity obtained for the four analyzed logs. Red circles indicate values of deviation form theoretical linearity corresponding to the salts critical $\mathrm{RH}$ levels allowing determining the presence of $\mathrm{Mg}\left(\mathrm{NO}_{3}\right)_{2}(53 \%), \mathrm{NH}_{4} \mathrm{NO}_{3}$

\begin{tabular}{|c|c|c|c|c|c|c|c|c|c|c|c|}
\hline \multicolumn{2}{|c|}{$\log 1$} & \multicolumn{4}{|c|}{$\log 4$} & \multicolumn{2}{|c|}{$\log 8$} & \multicolumn{4}{|c|}{ Trunk } \\
\hline $\mathrm{t}(\mathrm{nm})$ & $\mathrm{V}_{\text {ads }}(\%)$ & $\%$ & $\mathrm{t}(\mathrm{nm})$ & $\mathrm{V}_{\text {ads }}(\%)$ & $\%$ & $\mathrm{t}(\mathrm{nm})$ & $\mathrm{V}_{\text {ads }}(\%)$ & $\%$ & $\mathrm{t}(\mathrm{nm})$ & $\mathrm{V}_{\text {ads }}(\%)$ & $\%$ \\
\hline 0.11 & 3.58 & 10 & 0.11 & 4.53 & & 0.11 & 4.07 & & 0.11 & 2.80 & \\
\hline 0.19 & 5.65 & 20 & 0.19 & 6.95 & & 0.19 & 6.35 & & 0.19 & 4.40 & \\
\hline 0.25 & 7.24 & 30 & 0.25 & 9.00 & & 0.25 & 8.25 & & 0.25 & 5.78 & \\
\hline 0.31 & 8.64 & 40 & 0.31 & 10.95 & & 0.31 & 10.10 & & 0.31 & 7.17 & \\
\hline 0.37 & 10.51 & 50 & 0.37 & 12.79 & & 0.37 & 11.61 & & 0.37 & 8.78 & \\
\hline 0.44 & 13.78 & 60 & 0.44 & 15.04 & & 0.44 & 13.57 & & 0.44 & 10.62 & \\
\hline 0.53 & 19.53 & 70 & 0.53 & 18.73 & 70 & 0.53 & 16.75 & 70 & 0.53 & 12.74 & 70 \\
\hline 0.65 & 28.63 & 80 & 0.65 & 24.04 & 80 & 0.65 & 21.48 & 80 & 0.65 & 15.24 & 80 \\
\hline
\end{tabular}


Bertolin C., Strojecki M., de Ferri L., Grottesi G., Siani A. M.

\begin{tabular}{|c|c|c|c|c|c|c|c|c|c|c|c|}
\hline 0.81 & 44.94 & 90 & 0.81 & 32.68 & 90 & 0.81 & 28.30 & 90 & 0.81 & 19.19 & 90 \\
\hline 0.92 & 66.048 & 93 & 0.88 & 34.91 & 93 & 0.88 & 30.72 & 93 & 0.88 & 20.72 & 93 \\
\hline 1.00 & 90.81 & 98 & & & & & & & & & \\
\hline
\end{tabular}

The $t_{\max }$ value i.e. the maximum thickness of water film adsorbed at $93 \%$ of $\mathrm{RH}$ on the surface of the sample collected by each log was calculated according to Bratasz et al. [27] and then referred to the trunk element. Values of 2.3, 1.5,1.3 and 0,8 nm were found for Log1, $\log 4$, Log8 and the Trunk, respectively. This calculation was based on two preliminary assumptions: i) the mass of adsorbed water changes linearly when the sample representative of a Log is not affected by salts presence; ii) the effective diameter of water molecule is equal to $0.26 \mathrm{~nm}$. Parallel, also the number of water monolayers adsorbed by each sample could be calculated, being 9, 4,3 and 2 for $\log 1, \log 4, \log 8$ and the Trunk, respectively. These assumptions are reliable because plotting data reported in Table 2, a straight-line graph is expected if the water layer can grow freely on the entire surface of the sample since water volume adsorbed is a product of surface area and water layer thickness [25]. Deviations from linearity occur in presence of condensation phenomena generally due to deliquescent salts responsible for an extra amount of water. During our laboratory measurements, the point where the trend line deviates from the linearity specifies the type of the dominant salt in the sample. Results shows the most affected elements are respectively $\log 1$ and 4, while Log8 remains quite safe from salts crystallization. Summing up, the identified phases well match with both the environmental conditions and the historical use of the warehouse. The presence of $\mathrm{NaCl}$, in fact, can be
imputed to the marine setting as well as to its utilization for conservation and dehydration of
fish, in turn accountable for the presende of nitrates $[25,28,29]$.
Attenuation curves obtained by AE measurements [25] show a strong amplitude decrease
with distance from the PLB event. As stated in literature, the alteration degree (including the
presence of rot) and the material moisture content can be detected using AE data [30]. Also in this study, in fact, differences were observed for the studied logs, containing different amounts

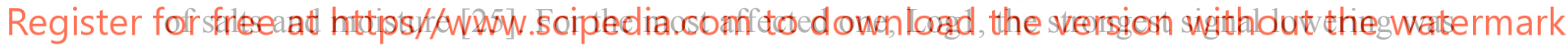
found if compared to the other wooden elements [25]. Considering that AE waves propagate as plane waves with a 1D front of the simple harmonic wave travelling through the absorptive medium without diffusion attenuation [31], an exponential absorption- scattering equation can be extracted [25]:

$$
\left|A_{x}-A_{T H R}\right|=A_{0} e^{-k x}
$$

being $A_{x}$ the amplitude at distance $\mathrm{x}$ from the PLB point (dB), $A_{0}$ the maximum amplitude at the source (i.e. source distance $=0)(\mathrm{dB}), A_{T H R}$ a constant background amplitude, $k$ the amplitude attenuation factor $\left(\mathrm{cm}^{-1}\right)$ and $x$ the source-sensor distance $(\mathrm{cm})$. The proposed equation resembles the hydration model already proposed in literature [32] to explain the wave propagation on materials surfaces at different hydration degrees.

Salts only barely affected the detection capability of sensors, since signals were registered for almost all the distances [25]. Notwithstanding the very high relative humidity and low temperature $\left(85 \%\right.$ and $\left.2{ }^{\circ} \mathrm{C}\right)$ conditions of the basement, the highest values were registered on the trunk, while the highest amplitude attenuation was found for Log1. Consequently, differences between the acoustic wave attenuation behavior in the three decayed Logs can be related to their decay condition. 
Analogues results on the type and level of decay of the monitored wooden elements, as well as some limits of the applied techniques can be underlined looking at the data obtained by the three used moisture meters (Figure 4). Here, original readings were analyzed in comparison to the reference Log demonstrated to be safe and dry i.e. the Trunk. An equation (i.e. eq.2), that resemble the definition of $\mathrm{MC}$ was used to conduct such analysis:

$$
\frac{\left(M C_{\text {Log, } i}-M C_{\text {Trunk }}\right)}{M C_{\text {Log, } i}} * 100
$$

In the plot, values of ca. 28-30 becomes therefore proxy for assessing the Fiber saturation Point (FSP) within wood. Lower values proxy representative of adsorbed moisture which can modify bound water (BW) embedded in the cell wall through adsorption and desorption; Higher values proxy representative of free water $(\mathrm{FW})$ that fills the wood cavities, once having filled the wooden cells. Within each $\log$ (i.e. $\log 1=\mathrm{L} 1 ; \log 4=\mathrm{L} 4 ; \log 8=\mathrm{L} 8)$, differences in the average values of $\mathrm{MC}$ are representative of optimal conditions for specific type of decay within the sensitive measurements field of the three instruments (i.e. areas highlighted in Figure 3). In the case of the Capacitive moisture meter (red dataset in Figure 4), it demonstrates a low accuracy in discriminating between different $\mathrm{MC}$ level among Log 1,4 and 8 as they result almost at the same MC range between 76 and 79 (Unit: $100 *$ MC (\%)). Notwithstanding a weak linear increase among them exists; $\log 1$ being the wooden element where a higher content of water is detected which resembles values of FW i.e. liquid water embedded in wooden cavities. In a similar way, the resistive moisture meter (black dataset in Figure 4) shows similar results with

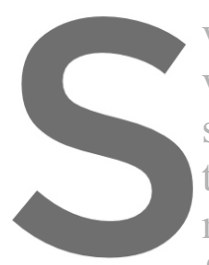
values resembling MC in a range between 76
values are lower than $0.02 \mathrm{MOhm}$ in a low
species (although the calibration done autor
temperature. In addition, although the physical pri
meters are strongly affected by the presence of first case they cause reflection of the signal wit
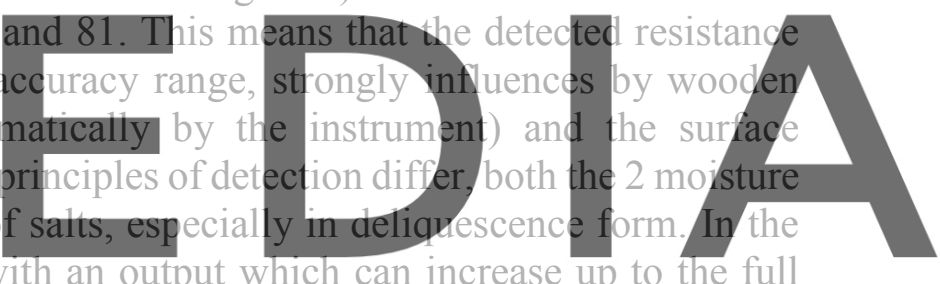

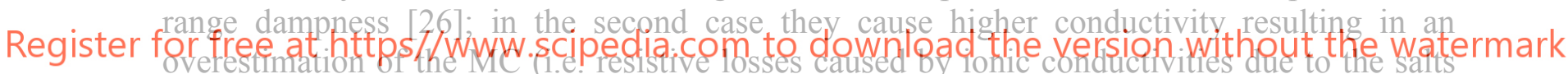

presence). Finally, in the case of the capacitive moisture meter, physical heterogeneities or micro blistering (as in the presence of fuzzy wood appearance in Logl and 4) can additionally cause misleading high dampness values. For this reason, results from both the two methods have low significance in this case study, although they demonstrate presence of salts in deliquescence forms within the first $2 \mathrm{~cm}$ pf the superficial level of the Logs. At the opposite the microwave moisture meter (blue dataset in Figure 4), provides more detailed information about the level of decay in the Logs. Such method can detect that the whole Log8 is not affected by high value of MC. This means that -in average - the bulk material is not damaged by salt weathering and still in good condition, while is only the superficial layer that is affected by the presence of a thin layer of salts in deliquescence form (output provided by the 2 other moisture meters). This is confirmed by the measurements done with the vacuum microbalance that detected $1.3 \mathrm{~nm}$ of maximum thickness of water film adsorbed at $93 \%$ of $\mathrm{RH}$ corresponding to 3 water monolayers. Different is the situation for $\log 4$ and 1 which equally demonstrates the probability of having average value of bulk material at the FSP, or a thick superficial layer contaminated by deliquescent salts which reflects the penetrating electromagnetic field thus overestimating the output and the MC values. Although we know, from the measurements 
conducted with the microbalance, that such hypothesis if the most likely, however with the measurements from the microwave moisture meter only such discrimination is not possible. The comparison with the microbalance results demonstrates that already 4 monolayers of water (i.e. a maximum thickness of $2.3 \mathrm{~nm}$ ) at the surface of the material are sufficient to eventually overestimated MC values at the level of FSP thus invalidating the capability of the instrument to penetrate deeper layer of the material.

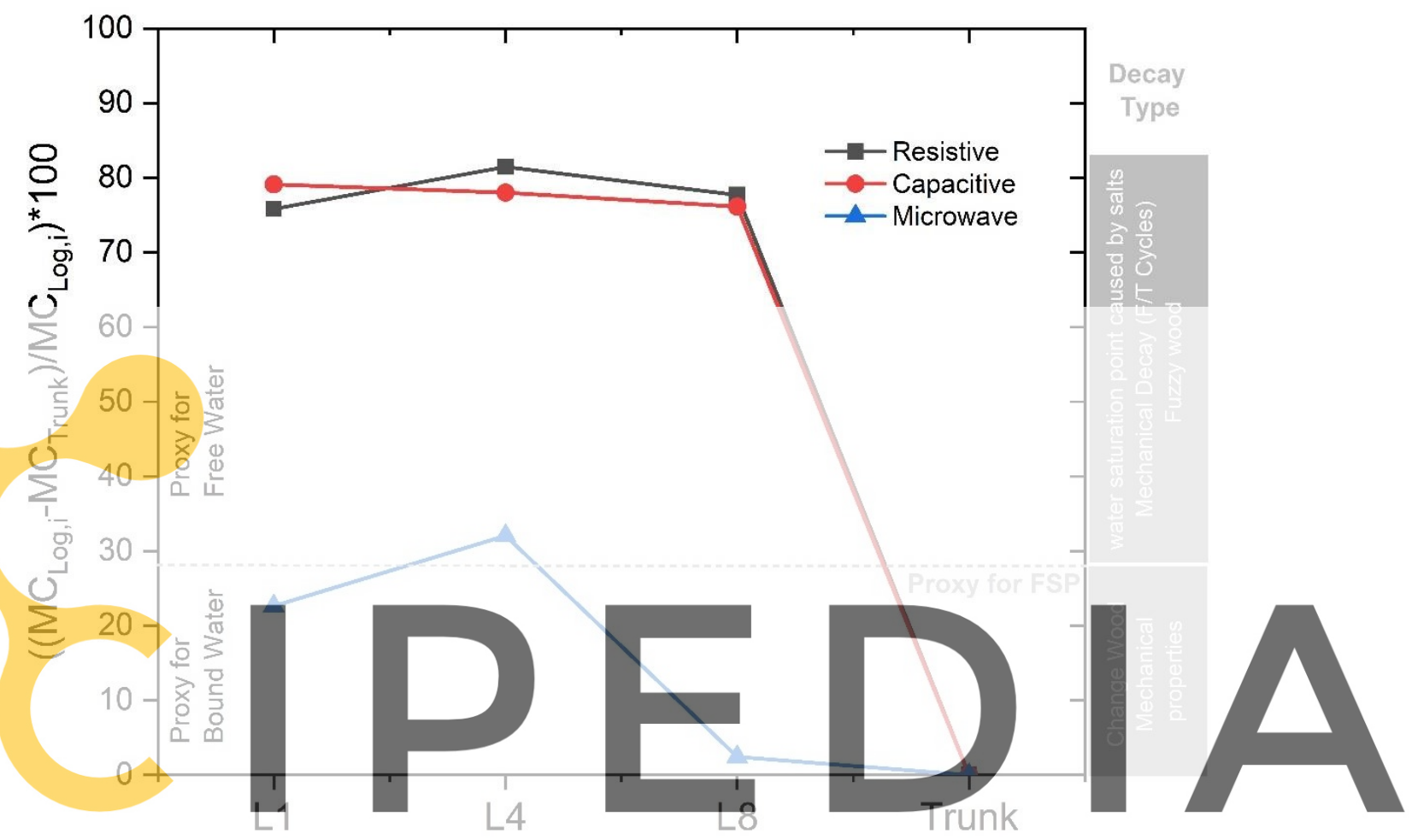

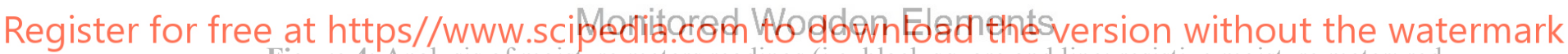

Figure 4: Analysis of moisture meters readings (i.e. black square and line: resistive moisture meter; red

circle and line: capacitive moisture meter and blue triangle and line: microwave moisture meter), elaborated to resemble the definition of MC in reference to the Trunk as dried wooden element. Values of ca. 28-30 are a proxy for the Fiber saturation Point (FSP). Lower values are proxy representative of adsorbed moisture which modifies bound water embedded in the cell wall; Higher values are proxy representative of free water that fills the wood cavities. On the right, the effects of such MC modifications are described as type of visible decay.

\section{CONCLUSIONS}

The proposed study of four spruce logs form a $20^{\text {th }}$ century warehouse in Trondheim (Norway) involved a multi-technique approach allowing obtaining complementary information concerning the state of conservation of such structural elements.

The contamination degree of wood by salts has been evaluated performing water absorption-desorption measurements by means of a vacuum microbalance that permitted the identification of the main phases crystallizing inside the wooden structures and on the surfaces, as well as the maximum thickness of the water film adsorbed on the samples surface. Outcomes indicated how the most contaminated and hydrated elements were Log1 and 4, while Log8 and the Trunk resulted quite safe. Parallel, AE measurements evidenced differences in the 
attenuation curves get on the four elements as a function of the alteration degree. Particularly a direct connection between the wood hydration degree and how acoustic waves propagates into the material, or more precisely on the material surface. These findings are also confirmed by the measurements conducted with different moisture meters that, in the area of sensitiveness i.e. their measurement fields, have demonstrated to be effective in (i) detecting the presence of salts in deliquescence form already after the appearance of very few monolayers of water as the case of the resistance and capacitive methods and (ii) in assessing an average level of MC in the bulk material that remains representative of the overall conditions of material also under extreme environmental conditions as the case of the microwave moisture meter working on Log8 during this monitoring campaign (i.e. environmental conditions with high RH, low $\mathrm{T}$ conditions; material with high contents of salts in deliquescent form and decayed by salt weathering and fuzzy appearance). However, also this last method has demonstrated its limitation because already 4 monolayers of water (i.e. $2.3 \mathrm{~nm}$ ) at the wooden surface cause signal reflections which overestimate the $\mathrm{MC}$ thus invalidating the capability of the instrument to penetrate deeper layer of the material.

Acknowledgements. The authors are grateful to Prof. Eileen Garmann Johnsen for her kind support during the monitoring campaign. The activity has been possible thanks to the Norwegian Research Council funded "SyMBoL-Sustainable Management of Heritage Building in a Long-term Perspective" Project (Project No. 274749). This research was funded in part by the statutory research fund of ICSC PAS

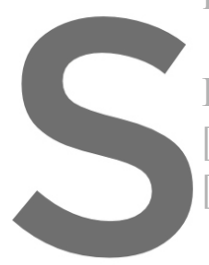

\section{REFERENCES}
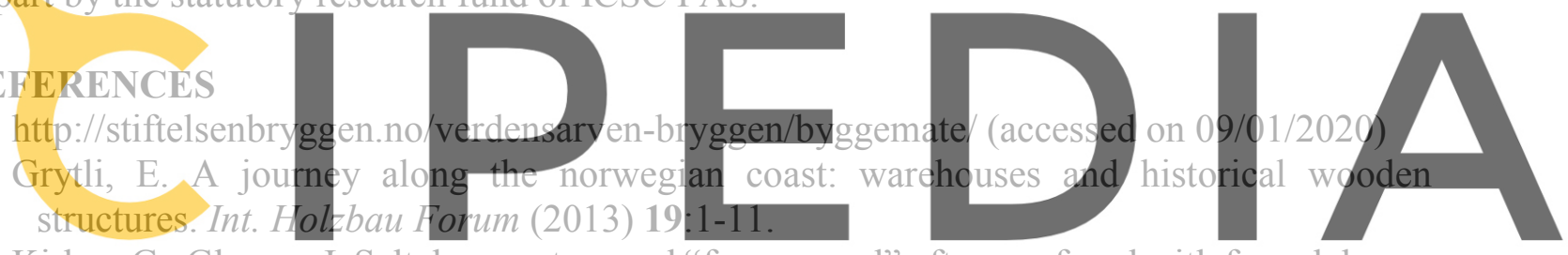

[3] Kirker, G., Glaeser, J. Salt damage to wood "fuzzy wood" often confused with fungal decay.

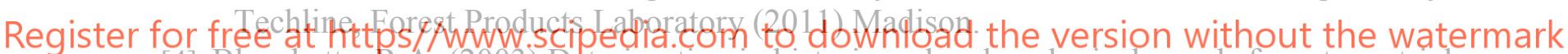

[4] Blanchette, R.A. (2003) Deterioration in historic and archaeological woods from terrestrial sites. In: R.J. Koestler et al. (Eds): Art, biology, and conservation: biodeterioration of works of art. The Metropolitan Museum of Art, New York, pp. 328-347.

[5] Blanchette, R.A., Held, B.W., Farrell, R.L. Defibration of wood in the expedition huts of Antarctica: an unusual deterioration process occurring in the polar environment. Polar $\operatorname{Rec}(2002)$ 38:313-322.

[6] Kim, D.W., Kim, C.W., Han, S.H., Chung, Y.J., Han, G.S. Flame retardant treatment's effects and detection method on wooden buildings' pigment layer. J. Korean Wood Sci. Technol. (2014) 42:393-406.

[7] Catelli, E., Bănică, F.G., Bănică, A. Salt efflorescence in historic wooden buildings. Herit Sci. (2016) 4:31-44.

[8] Madhoushi, M., Eimanian, J., Ansell, M.P. Non destructive and laboratory evaluation of strength of decayed wood members in a historic construction located in Gorgan (North of Iran). In: Structural analysis of historic construction: preserving safety and significanceproceedings of the 6th international conference on structural analysis of historic construction, SAHC08, Vol 1 (2008) pp. 469-472.

[9] Campos, .AF., de Macedo, L.B., de Castro, E., Silva Bortolucci, M.A.P., Lahr, F.A.R. 
Evaluation of health conditions of wooden structures of the former slave quarters of farm Santa Maria do Monjolinho, located in the state of São Paulo, Brazil. Adv. Mater. Res. (2013) 778:1096-1101.

[10] Piotrowska, M., Otlewska, A., Rajkowska, K., Koziróg, A., Hachułka, M., NowickaKrawczyk, P., Wolski, G.J., Gutarowska, B., Kunicka-Styczyńska, A., Zydzik-Białek, A. Abiotic determinants of the historical buildings biodeterioration in the former Auschwitz II-Birkenau concentration and extermination camp. PLoS ONE (2014) 9: e109402-1-12.

[11] Jakiela, S., Bratasz, L., Kozlowski, R. Acoustic emission for tracing the evolution of damage in wooden objects. Stud. Conserv. (2007) 52:101-109.

[12] Strojecki, M., Łukomski, M., Krzemień, L., Sobczyk, J., Bratasz, Ł. Acoustic emission monitoring of an eighteenth-century wardrobe to support a strategy for indoor climate management. Stud. Conserv. (2014) 59:225-232.

[13] Le Conte, S., Vaiedelich, S., Thomas, J.H., Muliava, V., de Reyer, D., Maurin, E. Acoustic emission to detect xylophagous insects in wooden musical instrument. J. Cult. Herit. (2015) 16:338-343.

[14] Łukomski, M., Strojecki, M., Pretzel, B., Blades, N., Beltran, V.L., Freeman, A. Acoustic emission monitoring of micro-damage in wooden art objects to assess climate management strategies. Insight (2017) 59:256-265.

[15] Łukomski, M., Beltran, V., Boersma, F., Druzik, J., Freeman, A., Strojecki, M., Learner, T., Taylor, J. Monitoring acoustic emission in an epidemiological pilot study of a collection of wooden objects. Stud Conserv. (2018) 63:181-186.

[16] Carpinteri, A., Lacidogna, G. Damage evaluation of three masonry towers by acoustic emission. Eng. Struct. (2007) 29:1569-1579.

[17] Niccolini, G., Carpinteri, A., Lacidogna, G., Manuello, A. Acoustic emission monitoring of the syracuse athena temple: scale invariance in the timing of ruptures. Phys. Rev. Lett. (2011) 106:108503-1-108503-4.

[18] Niccolini, G., Manuello, A., Marchis, E., Carpinteri, A. Signal frequency distribution and natural-time analyses from acoustic emission monitoring of an arched structure in the Castle of Racconigi. Nat. Hazards Earth. Syst. Sci. (2017) 17:1025-1032.

[19] Kourkoulis, S.K. Recent advances in structural health monitoring of restored elements of marble monuments. Procedia Struct. Integr. (2018) 10:3-10.

[20] Carpinteri, A., Lacidogna, G., Niccolini, G. Acoustic emission monitoring of medieval towers considered as sensitive earthquake receptors. Nat. Hazards Earth Syst. Sci. (2007) 7:251-261.

[21] Carpinteri, A., Lacidogna, G., Invernizzi, S., Accornero, F. The sacred mountain of Varallo in Italy: seismic risk assessment by acoustic emission and structural numerical models. Sci. World. J. (2013) 170291-1-17029111

[22] Hsu, N., Simmons, J.A., Hardy, S. An approach to acoustic emission signal analysistheory and experiment. Matls. Eval. (1977) 35:100-106-

[23] ASTM E976-15: 2015. Standard guide for determining the reproducibility of acoustic emission sensor response

[24] ASTM E2374-16: 2016. Standard guide for acoustic emission system performance verification

[25] Bertolin, C., de Ferri, L., Grottesi, G., Strojecki, M. Study on the conservation state of wooden historical structures by means of acoustic attenuation and vacuum microbalance. 
Wood Sci. Technol. (2020) 54: 203-226.

[26] Camuffo, D., Bertolin C. Towards standardisation of Moisture Content measurement in Cultural Heritage Materials. e-Preservation Science (2012) 9:23-35.

[27] Bratasz, Ł., Kozlowski, R., Kozlowska, A., Rachwal, B. Analysis of water adsorption by wood using the Guggenheim-Anderson-de Boer equation. Eur. J. Wood Prod. (2012) 70: 445-451

[28] Arthur, M.A., Siccama, T.G., Yanai, R.D. Calcium and magnesium in wood of northern hardwood forest species: relation to site characteristics. Can. J. For. Res. (1999) 29:339346.

[29] Li, D., Ou, J., Lan, C., Li, H. Monitoring and failure analysis of corroded bridge cables under fatigue loading using acoustic emission sensors. Sensors (2012) 12:3901-3915.

[30] Zhang, J., Yang, S., Hao, R., Gu, X. Amplitude attenuation laws of acoustic emission waves in plate structures. Tecnol, Ing. Mec. (2019) 94:67-74.

[31] Nadelman, E.I. Hydration and microstructural development of Portland limestone cementbased materials. Doctoral dissertation, Institute of Technology, (2016) Georgia

[32] Schindler, A.K., Folliard. K.J. Heat of hydration models for cementitious materials. $A C I$ Mater. J. (2005) 102:24-33. 